\title{
Influence of laser surface structuring of steel sheets on the mechanical properties of electrodeposited $\mathrm{ZnNi}$ coatings
}

\author{
Christian Stelter ${ }^{1, *}$ and Stefan Dieckhoff ${ }^{2}(\mathbb{D})$ \\ ${ }^{1}$ ZF Friedrichshafen Group, Car Chassis Technology, Dr.-Jürgen-Ulderup-Str.7, 32351 Stemwede, Germany \\ ${ }^{2}$ Fraunhofer-Institute for Manufacturing Technology and Applied Materials Research (IFAM), Adhesion and Interface Research, \\ Wiener Str.12, 28359 Bremen, Germany
}

Received: 16 November 2021 / Accepted: 23 January 2022

\begin{abstract}
The influence of laser surface structuring on the formation and the internal strength of electrodeposited $\mathrm{ZnNi}$ coatings on steel sheets was investigated. Surface structuring by extended direct laser interference patterning (xDLIP) was used to modify the cohesive strength in the ZnNi layer. An SEM analysis of the crystal structures shows perpendicular nucleation during $\mathrm{ZnNi}$ layer formation and areas of crosslinked crystalline structures, which results in an interlocking of crystal structures within the layer. The interlocked crystalline structure leads to an increase of the cohesive strength in the $\mathrm{ZnNi}$ layer, which was observed in roller peel tests according to DIN 1464 for adhesively bonded joints.
\end{abstract}

Keywords: Laser structuring / ZnNi coating / layer structure / adhesive bonding / roller peel test

\section{Introduction}

Besides aluminum, steel alloys remain the co-determining material in automotive engineering for lightweight construction in the current attempts to reduce the $\mathrm{CO}_{2}$ footprint. According to Pathberg [1], almost $75 \%$ of all new passenger cars are currently produced with a steel car body. Higherstrength steel alloys have undergone considerable development and can be manufactured economically using their established manufacturing and processing methods [2]. Also, in view of the development of electric driving, simple component geometries with optimal bending abilities will still be required to absorb high energies in the car body and increasing driving dynamics loads in the chassis.

To meet in-service relevant surface protection requirements, cathodic deposition processes are used for steel components in automotive industry, such as electrolytic galvanization or e-coating [3-7]. In contrast to the protection of visible car body components, where multilayer coating systems are used, the corrosion protection performance of coated chassis components is currently only tested under standard climatic conditions. Also, in automotive industry, surface protective coatings must provide an increasing variety of properties. In the past, the focus was primarily on corrosion protection of metal parts. Nowadays technical surfaces must provide additional

\footnotetext{
* e-mail: christian.stelter@zf.com
}

properties like abrasion resistance, self-cleaning or high adherence [8]. This entails new application and utilization properties in process design with subsequent adhesive bonding. As an alternative to conventional welding processes that would damage the previously deposited coating on steel sheets, adhesive bonding of electrolytically coated $\mathrm{ZnNi}$ steel offers a promising alternative for metal joining.

To achieve a long-term, durable adhesive bonding of coated steel sheets, not only the adherence of the $\mathrm{ZnNi}$ coating to the steel surface, but also the cohesive strength and the inner structure of the $\mathrm{ZnNi}$ layer must be considered. Conventional electrodeposited coatings do not fulfill these requirements in all cases and must be examined in detail when used for adhesive bonding.

Tape-galvanized and batch-galvanized steel surfaces show dependencies on the surface pretreatment with a view to the layer structure and the internal strength of the $\mathrm{Zn}$ layer [9-11]. However, it is not possible to transfer these results to electrodeposited $\mathrm{ZnNi}$ coatings due to the different crystal structure.

In general, the electrodeposited $\mathrm{ZnNi}$ layer with a $\mathrm{Ni}$ concentration of $12-16 \%$ has a crystalline fine-grained and unoriented structure with high hardness. The mechanical properties are mainly characterized by the chemically very stable gamma $(\gamma)$ phase $[12,13]$.

Münninghoff et al. [14] describe the crystal growth and the nucleation kinetics of an electrodeposited $\mathrm{Zn}$ layer. The results indicate that crystal growth is always oriented 
Table 1. Chemical composition of the steel used according to DIN EN 10130.

\begin{tabular}{llllll}
\hline Material & \multicolumn{5}{c}{ Chemical composition } \\
\hline DC01 & {$[\mathrm{m} \%]$} & $\mathrm{C}$ & $\mathrm{P}$ & $\mathrm{S}$ & $\mathrm{Mn}$ \\
\hline DIN 10130 & & 0.12 & 0.045 & 0.045 & 0.6 \\
\hline
\end{tabular}

Table 2. Properties of selected adhesive according to technical data sheet.

\begin{tabular}{lllllll}
\hline Adhesive & $\begin{array}{l}\text { Chemical } \\
\text { base }\end{array}$ & Curing & $\begin{array}{l}\text { Pot life } \\
{[\text { min. }]}\end{array}$ & $\begin{array}{l}\text { Viscosity } \\
{[\mathrm{mPa} \mathrm{s}]}\end{array}$ & $\begin{array}{l}\text { Density } \\
{\left[\mathrm{cm}^{3}\right]}\end{array}$ & $\begin{array}{l}\text { Tensile sheer } \\
\text { strength as per } \\
\text { DIN 53283 [MPa] }\end{array}$ \\
\hline $3 \mathrm{M}^{\mathrm{TM}} \mathrm{SW}^{\mathrm{TM}} \mathrm{DP} 490$ & $2 \mathrm{C}$ epoxy & $2 \mathrm{~h}$ at $65^{\circ} \mathrm{C}$ & 90 & Pasty & 1.0 & 30 \\
\hline
\end{tabular}

perpendicularly to the substrate surface. This crystallographic orientation is confirmed by Oriti et al. [15] in comparison with acid and alkaline electrodeposited $\mathrm{ZnNi}$ layers. Chao-hong et al. [16] also show an improved linear orientation of the crystal growth of a $\mathrm{ZnNi}$ layer at the interface to $\mathrm{Sn}-\mathrm{Zn}$ solders through heat treatment. Here, the growth rate decreases after a critical layer thickness of 6-10 $\mu \mathrm{m}$ and follows a parabolic orientation.

Furthermore, various investigations are known in which specifically bath compositions of the electrolyte or additives have a direct influence on the nucleation $[13,17,18]$. In this context Bishop et al. [20] generate vertical, equiaxial, and parallel crystal growth directions in relation to the substrate surface by means of adapted additives. In addition to the crystal structure of electrodeposited coatings, Unruh [20] describes so-called "crystal intergrowth", which generates an additional resistance against multidirectional mechanical stress due to their small crystalline crosslinked arrangement. This interlocked structure leads to higher strength in the coating layer. Assuming a crystal growth perpendicular to the substrate surface, specifically periodic surface (micro) structures could influence the crystalline growth direction, which leads to local crosslinked or interlocked areas in the $\mathrm{ZnNi}$ layer.

Periodic surface structures are used in various fields of surface application to optimize the functional properties. Comparing to conventional photolithographic or mechanical methods the laser micromachining has specific advantages like contactless treatment and easy adjustment of the parameters to generate a great variety of possible structures. Further Kietzig et al. [21] describe, that there are a lot of investigations via short pulse lasers to adapt use-orientated properties by specifically periodic surface structures for optical, hydrophobic or tribological applications. D'Alessandria et al. [22] and El-Khoury et al. [23] use the laser interference structuring for metal surfaces as an alternative to achieve periodic surface structures in the sub- $\mu \mathrm{m}$ range and high stock removal rates in only one processing step.

A possible application of periodic surface structures formed by laser interference patterning and its influences on crystal growth direction in $\mathrm{ZnNi}$ coatings is presented in this study.

\section{Experiments}

\subsection{Materials}

Thin steel sheets made of cold-rolled DC01 (Salzgitter Flachstahl $\mathrm{GmbH}$ ) were used for the investigations to comply with the typical requirements for sheet metals in automotive engineering. The steel is a general construction steel with a yield strength of $280 \mathrm{MPa}$. Its properties and chemical composition are shown in Table 1.

Roller peel samples are prepared according to DIN 1464 as thick $(250 \mathrm{~mm} \times 25 \mathrm{~mm} \times 2.5 \mathrm{~mm})$ and thin $(300 \mathrm{~mm} \times 25$ $\mathrm{mm} \times 0.5 \mathrm{~mm})$ sheets from the cold-rolled material DC01. For the later bonding the two sheets with different thicknesses of $2.5 \mathrm{~mm}$ and $0.5 \mathrm{~mm}$ (see also Fig. 7) and a heat-curing $2 \mathrm{C}$ epoxy $\left(3 \mathrm{M}^{\mathrm{TM}}\right.$ Scotch Weld $\left.{ }^{\mathrm{TM}} \mathrm{DP} 490\right)$ has been selected. The adhesive is cured according the technical data sheet at $65^{\circ} \mathrm{C}$ for $2 \mathrm{~h}$. Other adhesive properties are shown in Table 2.

\subsection{Surface structuring}

To find the best surface structure leading to an interlocked crystalline structure within the electrodeposited $\mathrm{ZnNi}$ layer, various surface contours were taken into account. A selection of contours can be seen in Figure 1. Assuming perpendicularly crystal growth and a constant layer thickness of $10 \mu \mathrm{m}$ the orientation growth should be limited after a few $\mu \mathrm{m}$ according to Münninghoff et al. [14] and Chao-hong et al. [16]. Taking this into account the convex contours (Fig. 1a) and (Fig. 1d) demonstrate the most possible crosslinked crystalline areas. Concave (Fig. 1b) and pyramid (Fig. 1c) contours do not show these favored crosslinked areas or have disadvantages regarding the manufacturing process, respectively. The correlation between contour shape, the repetition distance and technical manufacturing limits leads finally to a parameter set with the best conditions for the interlocked structures. Therefore, the convex contour with a repetition distance of $10 \mu \mathrm{m}$ and about $1-3 \mu \mathrm{m}$ thickness is used for the laser application in this study.

The laser structuring tests were carried out at Material Engineering Center Saarland (MECS). For the tests in this study, a high-power pulsed laser system of the Quanta-Ray 


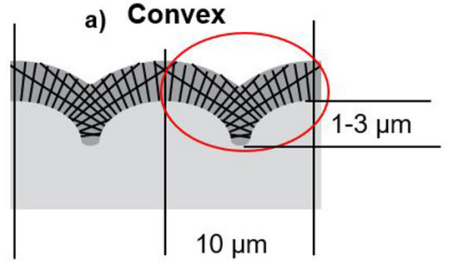

b) Concave

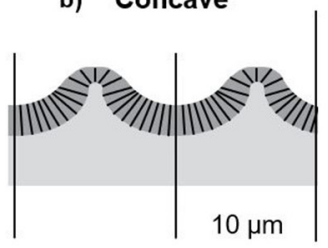

$\square$ ZnNi layer

$\square$ Substrate

- Growth direction

Crosslinked areas

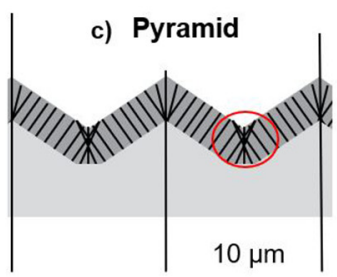

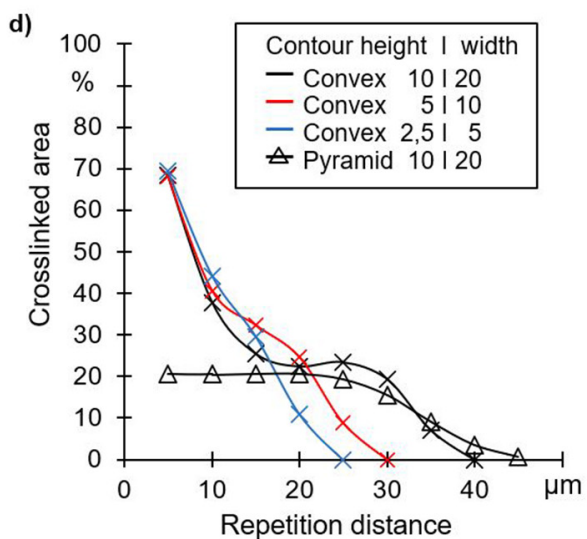

Fig. 1. Different contour shapes for laser structuring and their impact on crystalline growth direction (a-c) and resulting crosslinked area depending on repetition distance $(\mathrm{d})$.

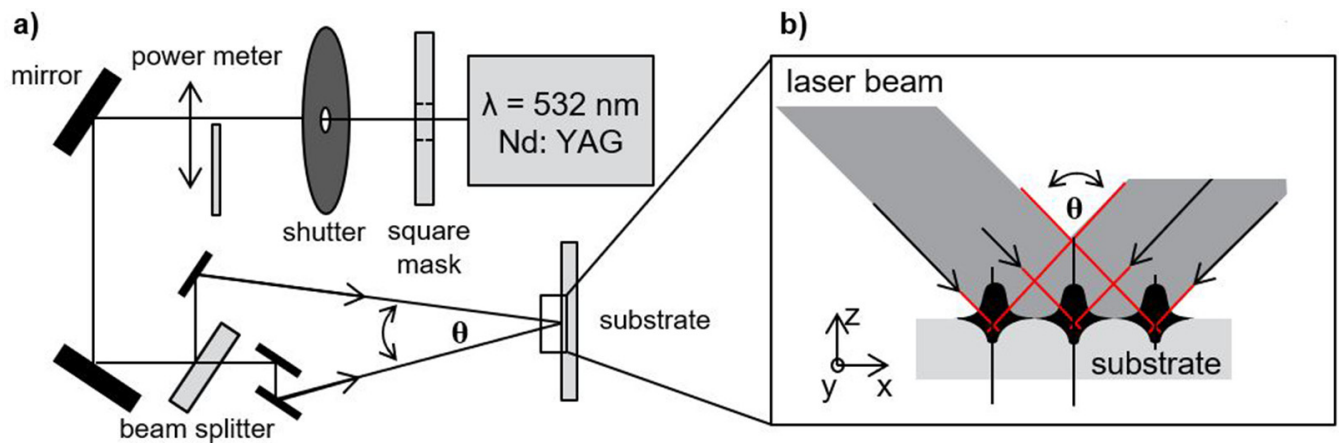

Fig. 2. (a) Schematic set-up for laser interference system and (b) resulting thermal affected surface zone according to D'Alessandria et al. [22].

Pro290 type by Newport Spectra Physics was used. This system operates via a lamp-pumped Nd:YAG laser rod. This extended direct laser interference patterning (xDLIP) was carried out using a wavelength from $532 \mathrm{~nm}$, a repetition frequency of $10 \mathrm{~Hz}$, and a pulse duration of 10 ns. To achieve the favored periodic structure, the primary laser beam was split into two coherent beams with an incidence angle $\theta=2.9^{\circ}$ to produces a two-dimensional linear pattern. A scheme of the beam interference and the thermal affected zone is shown in Figure 2 [22,24]. With rotating the sample to $90^{\circ}$ after the first line pattering, the entire surface of the steel alloy was structured using a primary laser power of $20 \mathrm{~W}$.

For direct comparison, identical steel sheet samples were grinded to the same roughness value of the laserstructured variant. The samples were grinded with a rotating 600 grit grinding wheel in transverse direction.

To simulate an ideally smooth surface, other samples were additionally polished after grinding. A rotating polishing wheel was used on which the polishing agent was applied as a paste or in the final step as an emulsion. The substrate surface was polished several times in different directions until a suitable gloss level was obtained.

To ensure the comparability of the sheet metal pairing in the roller peel test, both thin and thick sheets were structured identically on the adhesive surface. All samples with structured surfaces were pre-polished to avoid dimensional deviations from the steel rolling process.

A fourth sample variant with untreated surface was taken as a reference to the three structures. Due to the rolling production process, these untreated steel sheet samples had a higher surface roughness in delivery condition.

\subsection{Coating and bonding}

An electrodeposited alkaline ZnNi coating with $12-15 \% \mathrm{Ni}$ concentration was used. The steel sheet samples passed the standard pretreatment steps, such as degreasing, etching, electrolytic degreasing and pickling. Between the single pretreatment steps, the steel sheets were rinsed several times to prevent media carryover. The galvanization was performed in an electroplating plant at Dr.-Ing Max Schlötter GmbH \& Co. KG using the ZnNi electrolyte Slotoloy ZN 80 VX. The process was carried out with an adapted current density of $1.4 \mathrm{~A} / \mathrm{dm}^{2}$. Further properties of the galvanic process are shown in Table 3 . The $\mathrm{Ni}$ concentration and the $\mathrm{ZnNi}$ layer thicknesses were determined by using an energy dispersive X-ray fluorescence spectrometer (EDXRF) of the X-Ray XDL type from Fischerscope. The XRF were carried out with a tungsten tube source with beryllium window and a voltage of $30 \mathrm{kV}$. 
Table 3. Properties of the galvanic process with ZnNi Slotoloy ZN 80 VX electrolyte.

\begin{tabular}{llllllll}
\hline Coating method & Current density & $\mathrm{pH}$ & $\mathrm{Ni}$ & $\mathrm{Zn}$ & $\mathrm{NaOH}$ & Temperature & Platting time \\
\hline Rack & $1.4 \mathrm{~A} / \mathrm{dm}^{2}$ & 14 & $0.5 \mathrm{~g} / \mathrm{l}$ & $7.4 \mathrm{~g} / \mathrm{l}$ & $89.3 \mathrm{~g} / \mathrm{l}$ & $31^{\circ} \mathrm{C}$ & $70-80 \mathrm{~min}$ \\
\hline
\end{tabular}

Several spots were measured on the ZnNi layer along the sheet sample. For comparability reasons, a constant layer thickness of $10 \mu \mathrm{m}$ and $\mathrm{Ni}$ concentrations of $12-15 \%$ were aimed at.

An angle-dispersive X-ray diffraction (XRD) analysis in the $\mathrm{ZnNi}$ layer was done by Helmholtz Zentrum Berlin für Materialien und Energie GmbH (HZB) by using a 5-circle ETA (Seifert MZ VI) diffractometer. The XRD analysis was performed with $\mathrm{Cu}-\mathrm{K} \alpha$ radiation under the operation conditions $40 \mathrm{kV} / 45 \mathrm{~mA}$. Survey measurements were carried out in a $2 \theta$ range from $30^{\circ}$ to $140^{\circ}$ with a step size of $0.05^{\circ}$. For the subsequent residual stress analysis by means of the $\sin ^{2} \psi$ method, selected diffraction lines were measured in 0.1 steps of $\Delta \sin ^{2} \psi$. The slope of the regression fitted to the $d_{\psi}{ }^{h k 1}-\sin ^{2} \psi$ plots corresponds to the magnitude of the internal stresses. The thin and the thick sheet for the roller peel samples were bonded with the $2 \mathrm{C}$ epoxy. Before bonding, the samples were cleaned with isopropanol. The adhesive area is given by an overlap of $200 \mathrm{~mm}$ according to DIN 1464. In all variants, the adhesive gap was ensured by means of $0.2 \mathrm{~mm}$ glass spheres. The curing was carried out according to the adhesive specifications in Table 2. The thin sheet was peeled of under a defined angel later during test procedure.

\subsection{Analysis of surface structures}

The surface structures were evaluated by optical measurement using a confocal microscope of the MarSurf CM explorer type. This 3D measurement combines resolutions of $2 \mathrm{~nm}$ with a very high measuring speed. In addition, the roughness was also measured using tactile measurement with a measuring path of $\mathrm{Lt}=1.750 \mathrm{~mm}$ and a limit wavelength of $\lambda c=0.250 \mathrm{~mm}$ during crossing of the respective structure.

\subsection{SEM analysis of the layer structure}

For a more detailed analysis of the electrodeposited $\mathrm{ZnNi}$ layer, microsections were prepared from the surface structures by means of the focused ion beam (FIB) technique. These investigations were also carried out at MECS with a Dual Beam Workstation (type Strata DB 235 from FEI) consisting of a scanning electron microscope (SEM) in combination with a focus ion beam. In this combination secondary electrons separate from the surface were detected and used for imaging. Rough sections were prepared with a plasma point source and an acceleration voltage of $30 \mathrm{kV}$. For more precise microsections, a subsequently "post-polishing" with a gallium source at $5 \mathrm{kV}$ was used. In order to highlight the contrasts of different crystallographic orientations, an alternative detector (ion channeling) was used.

\subsection{Roller peel test}

The adhesive bond was tested according to DIN 1464 by means of roller peel tests. During the test, the thin sheet was peeled off at a defined angle by a pulling tool. A line load or peel resistance $[\mathrm{N} / \mathrm{mm}]$ was created in the bonded sample over a length of $200 \mathrm{~mm}$. The start and end of the peeling progress are usually not evaluated. Seven samples per configuration were peeled at a test speed of $100 \mathrm{~mm} / \mathrm{min}$ at room temperature. As a result of the peel test, the fracture pattern of the adhesive bond must also be considered. Here, the failure types illustrated in the DVS 3302 standard were used as basis for evaluation.

\section{Results}

\subsection{Surface structures}

The surface structures measured by confocal microscope before and after coating are shown in Figure 3. The untreated sample (Fig. 3a) has the highest roughness value of $\mathrm{Rz}=4.1 \mu \mathrm{m}$ obtained by tactile measurement. Before coating, the polished sample (Fig. 3b) shows a significantly smoother surface than the other variants with a roughness of $\mathrm{Rz}=0.1 \mu \mathrm{m}$. After coating, a roughness of $\mathrm{Rz}=0.5 \mu \mathrm{m}$ is detectable on the coated polished sample. The roughness values on the grinded sample with $\mathrm{Rz}=1.1 \mu \mathrm{m}$ (Fig. 3c) and the laser-structured sample with $\mathrm{Rz}=1.3 \mu \mathrm{m}$ (Fig. 3d) are only slightly higher after coating. A more precise representation of the laser structured sample can be seen in the cross-section given in Figure 4. The periodic convex structure shows a repeating distance of $10.2 \mu \mathrm{m}$ and a contour height of nearly $1 \mu \mathrm{m}$ in vertical distance.

The Ni concentration and layer thickness were measured by EDXRF. The results reveal a $\mathrm{Ni}$ concentration of $14-15 \%$ and a homogenous layer thickness of $10 \pm 1.5 \mu \mathrm{m}$, respectively. Post-measurements on the microsection resulted in minor local deviations.

\subsection{Analysis of the electrodeposited $\mathrm{ZnNi}$ layer}

The XRD diffractogram of the electrodeposited ZnNi layer is shown in Figure 5a. In Comparison to the respective interference positions of a ferrite (green) and a possible $\mathrm{ZnNi}$ mixed phase $\mathrm{Ni}_{5} \mathrm{Zn}_{2}$ (violet), a $\mathrm{ZnNi}$ alloy can be confirmed in the deposited layer. The residual stress analysis was carried out in the spectrum at $2 \theta=62.3^{\circ}$ (clear assignment to $\mathrm{Ni}_{5} \mathrm{Zn}_{21}$ ) by means of the $\sin ^{2} \psi$ method. Figure $5 \mathrm{~b}$ shows the measured lattice spacings against the inclination angle $\sin ^{2} \psi$. From the gradient of the regression line an averaged residual stress value of $+55 \pm 8 \mathrm{MPa}$ in $\sigma_{11}$ (longitudinal) and $+57 \pm 10 \mathrm{MPa}$ in $\sigma_{22}$ (transversal) could be calculated. 
Untreated
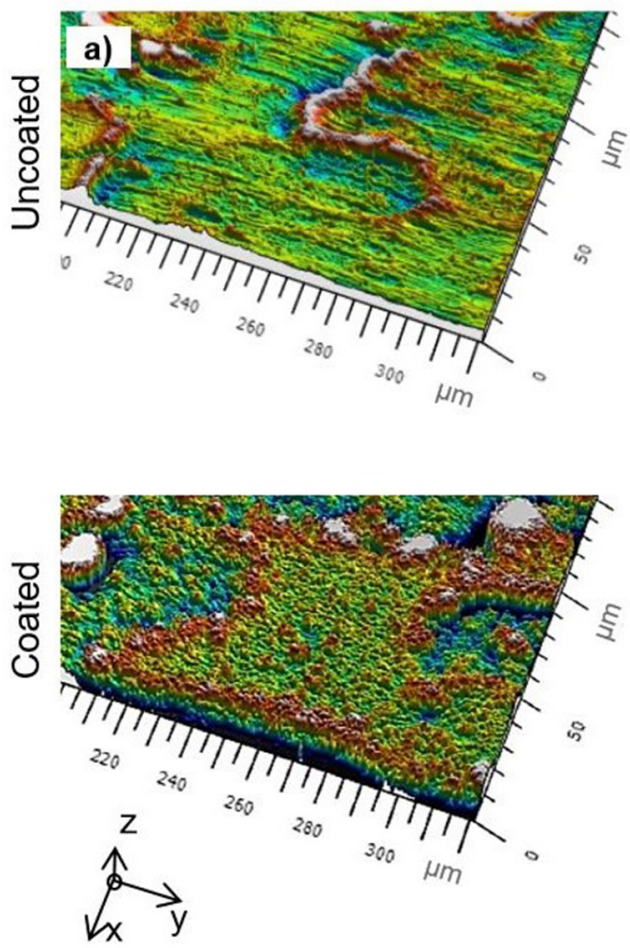

Grinded
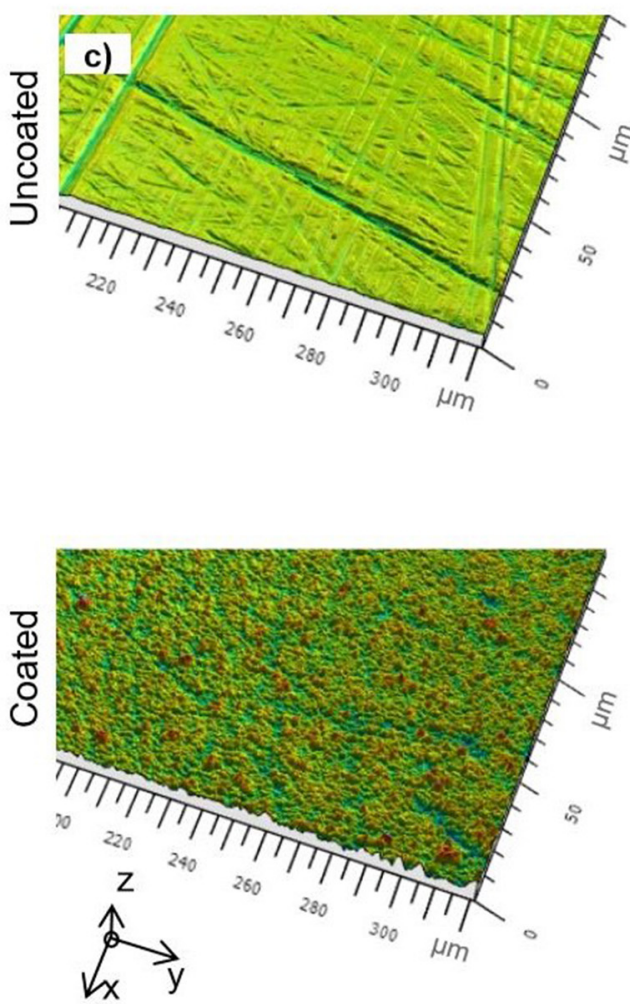

Polished
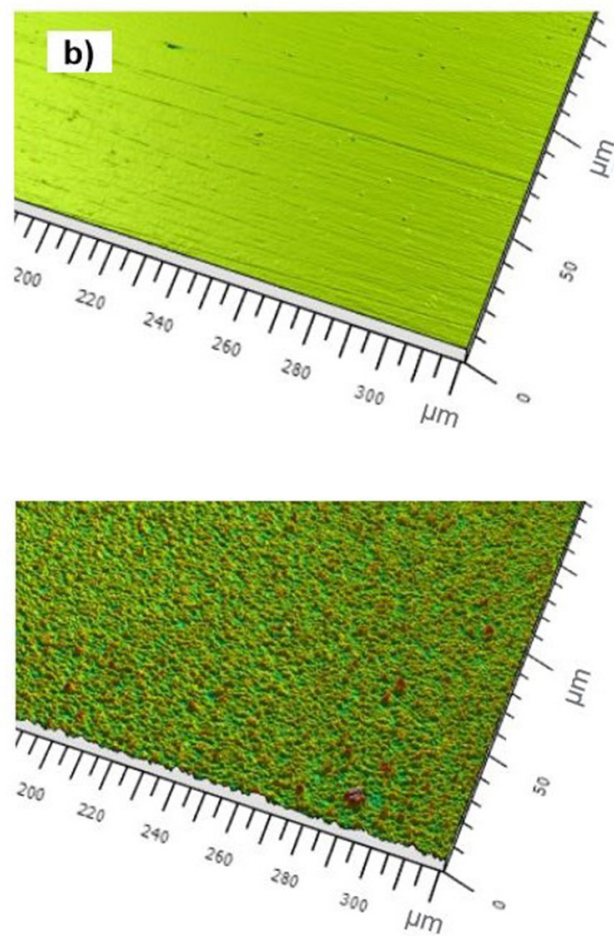

Laser-structured
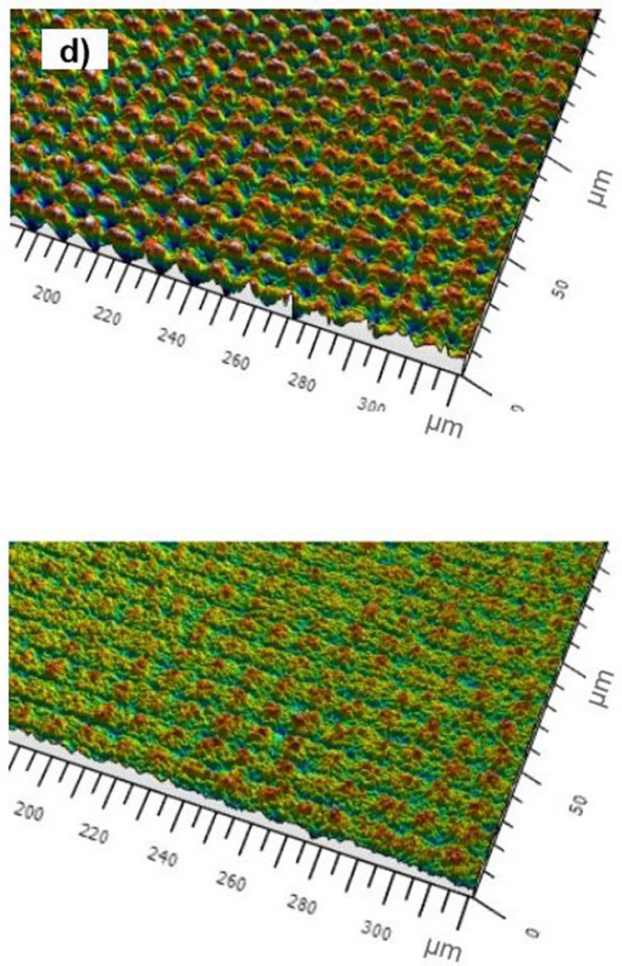

Fig. 3. Surface structures before and after coating, results from confocal microscopy. 


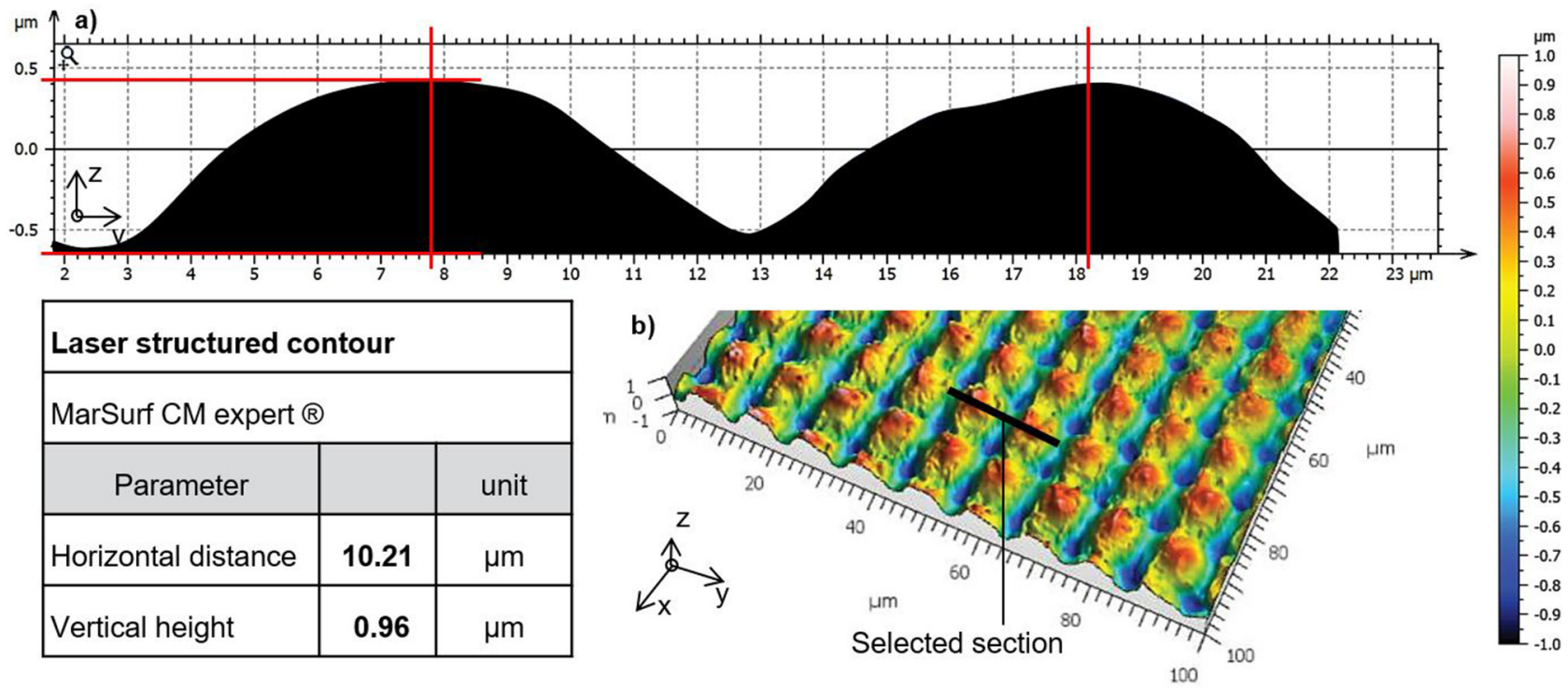

Fig. 4. Scanning confocal microscopic results. (a) Cross section and (b) more detailed 3D topography of xDLIP structured surface contour.

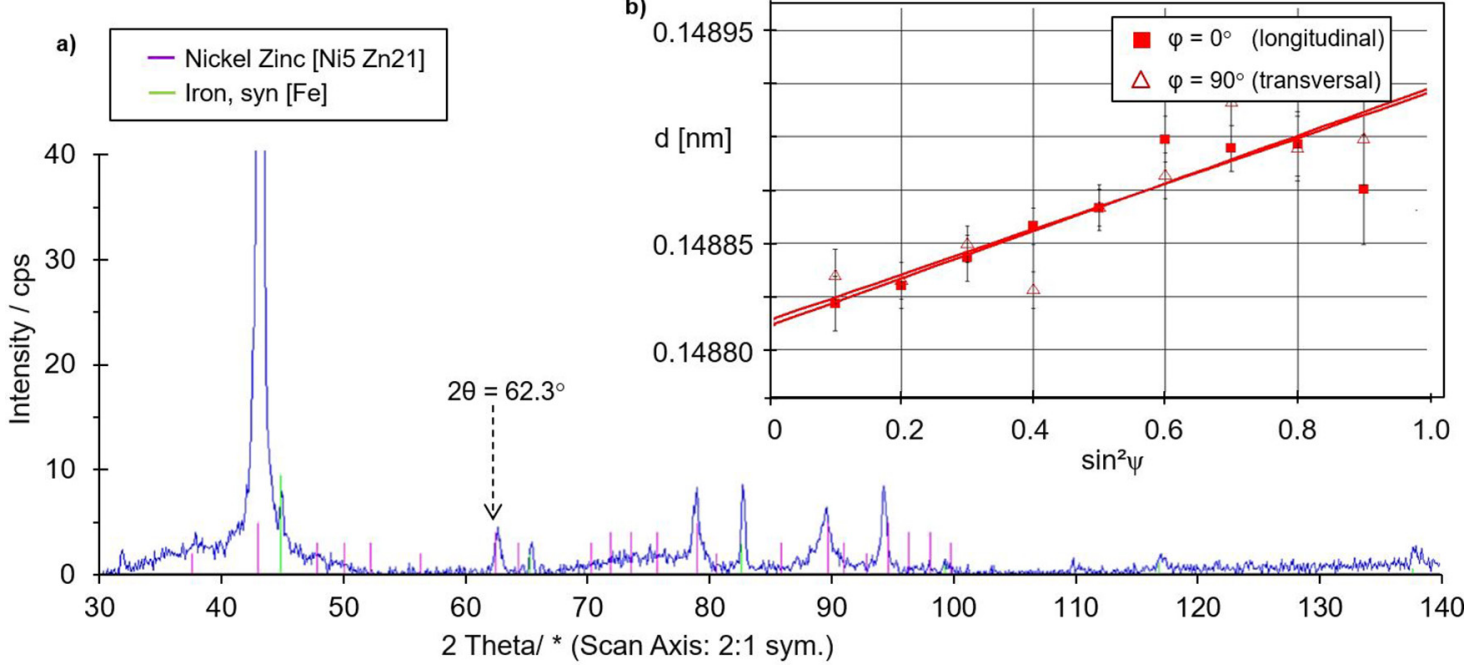

Fig. 5. (a) Diffractogram of the ZnNi layer with interference positions of Fe and Ni5Zn21, (b) residual stress analysis of the ZnNi layer in $\sigma 11$ and $\sigma 22$ direction at $2 \theta=62.3^{\circ}$.

Figure 6 shows the various surface structures studied by SEM analysis of microsections prepared by FIB. The orientation of crystalline structures of the $\mathrm{ZnNi}$ coating can be clearly identified by the high-contrast mode. The microsection of the untreated sample (Fig. 6a) shows column-shaped crystal structures perpendicular to the substrate surface. The crystalline structures of the polished sample (Fig. 6b) also show identical columns that are almost perpendicular to the surface. The microsection of the grinded sample (Fig. 6c) shows a scaled, small-crystalline structure with occasional crystal intergrowth areas. The sample of the laser-structured surface (Fig. 6d) exhibits the expected pronounced interlocked structure in the transition areas of the contour repetitions. In these areas, a very small crystalline structure is detectable, while the crystal structure in the extension of the spherical areas is formed in a columnshaped manner without any interlocking. Table 4 shows the respective structural properties in summary. The interlocked growth direction is continued in the investigated $\mathrm{ZnNi}$ layer up to a thickness of $10 \mu \mathrm{m}$.

\subsection{Investigations of peel resistances}

In order to evaluate the influence of the surface structuring on the internal layer strength, only the results of the peel tests with a failure within the $\mathrm{ZnNi}$ layer are compared. 

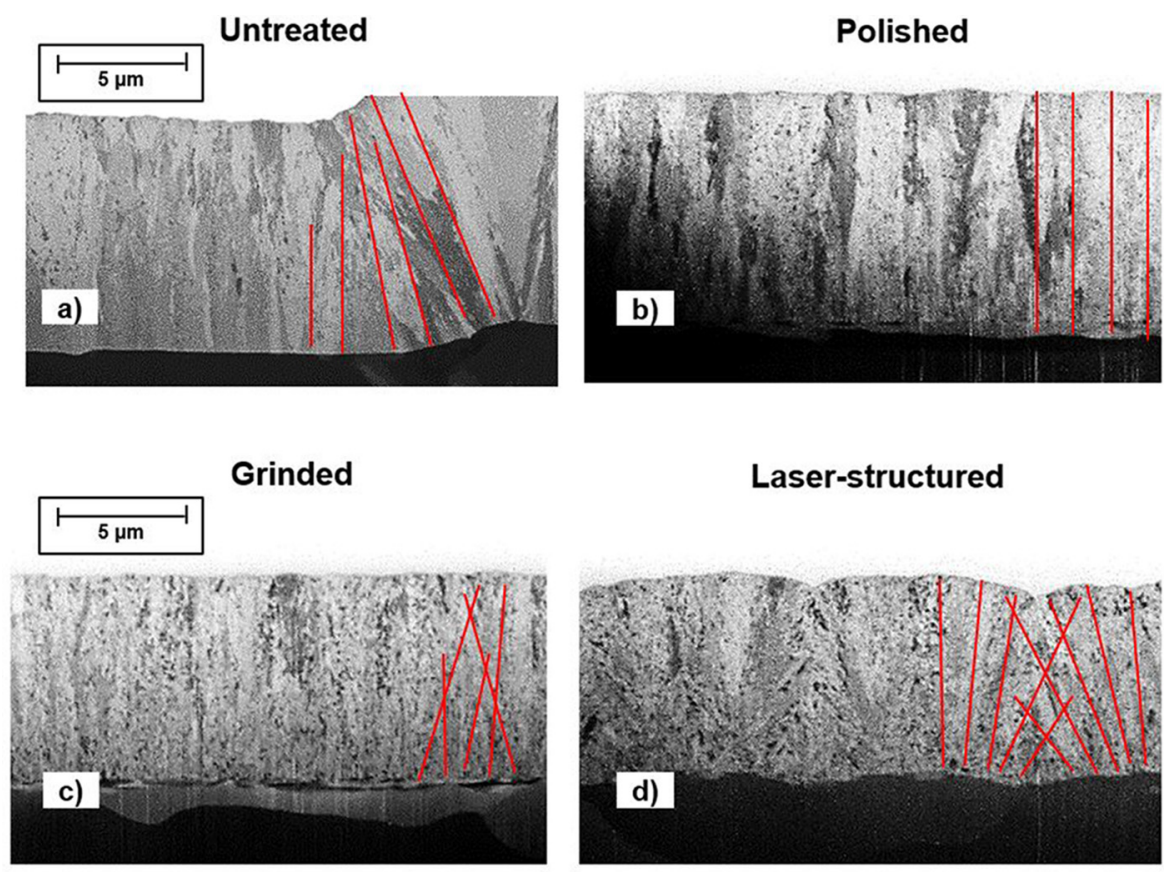

\section{Laser-structured}

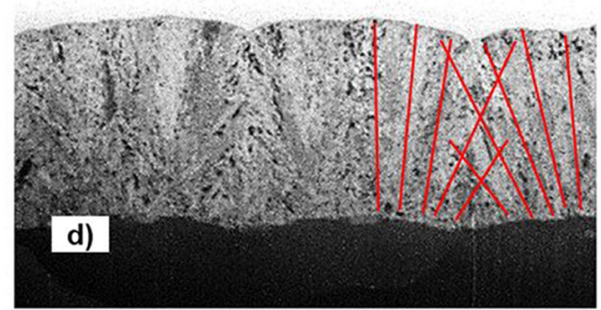

- Schematic column-shape growth direction

Fig. 6. SEM microsections of the $\mathrm{ZnNi}$ layer of the different structuring variants.

Table 4. Characteristics of the different structuring variants.

\begin{tabular}{lllll}
\hline Structure & Untreated & Polished & Grinded & Laser-structured \\
\hline Rz before & $4.1 \mu \mathrm{m}$ & $0.1 \mu \mathrm{m}$ & $1.0 \mu \mathrm{m}$ & $1.1 \mu \mathrm{m}$ \\
$\mathrm{Rz}$ after & $5.3 \mu \mathrm{m}$ & $0.5 \mu \mathrm{m}$ & $1.1 \mu \mathrm{m}$ & $1.3 \mu \mathrm{m}$ \\
Crystal structure & Column shape & Column shape & Small-crystalline & Small-crystalline \\
\hline
\end{tabular}

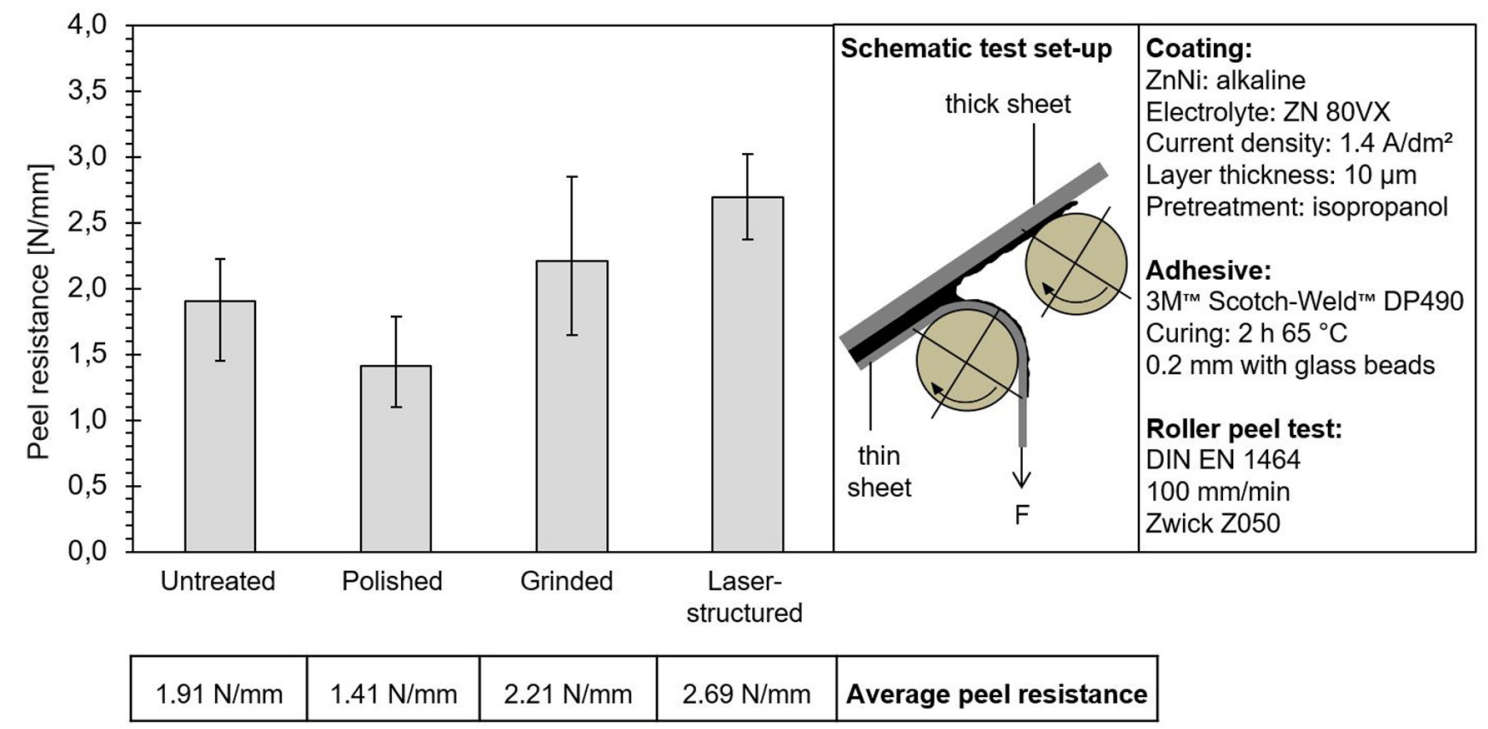

Fig. 7. Peel resistances achieved in roller peel test DIN 1464. 

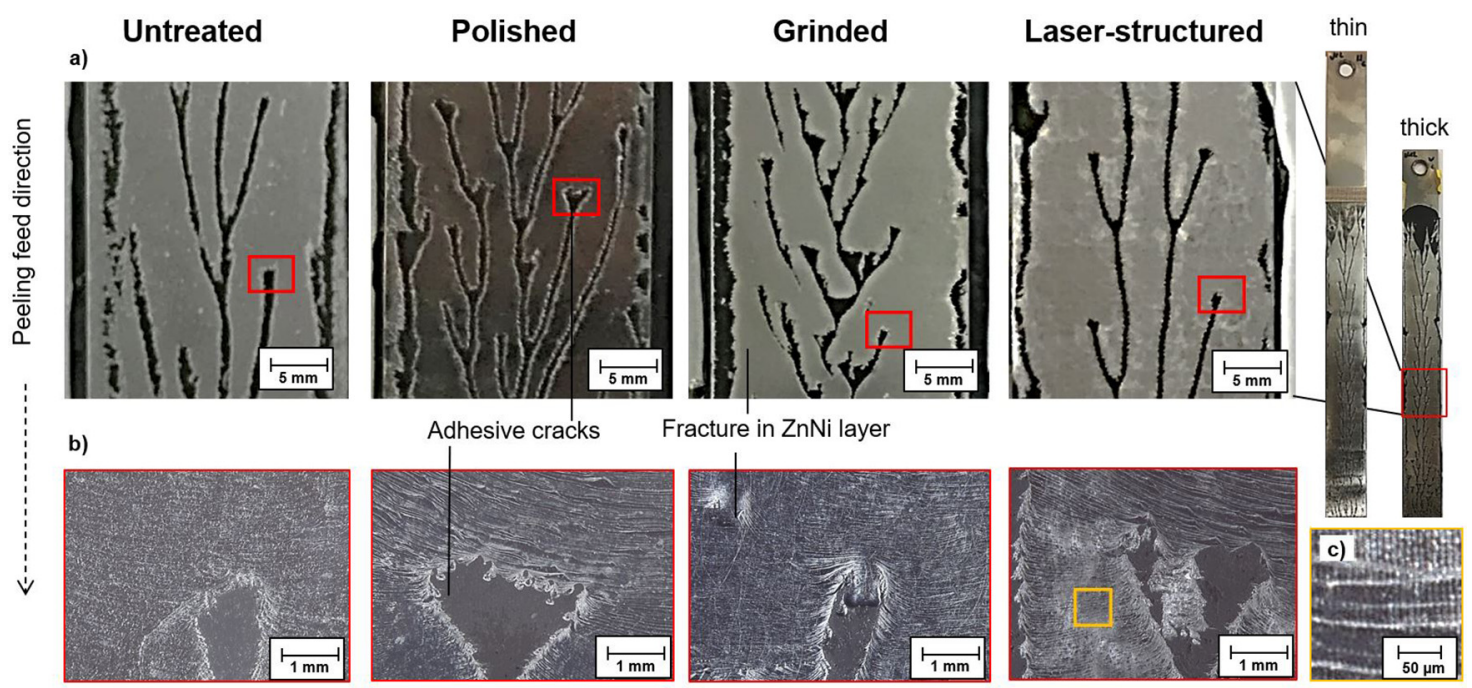

Fig. 8. Fracture pattern after roller peel test from $\mathrm{ZnNi}$ coated steel sheets.

Results and general conditions are given in Figure 7. Here, the untreated reference sample shows an average peel resistance of $1.91 \mathrm{~N} / \mathrm{mm}$. The polished sample has a lower peel resistance of $1.41 \mathrm{~N} / \mathrm{mm}$. The grinded sample shows an increase of the peel resistance to $2.21 \mathrm{~N} / \mathrm{mm}$ and, in case of the laser-structured sample, a further increase to $2.69 \mathrm{~N} / \mathrm{mm}$ is detectable. The variations of the $\min / \max$ values in the range of $\pm 0.5 \mathrm{~N} / \mathrm{mm}$ are comparable for all samples. Only in the case of the grinded samples are the deviations slightly higher.

\subsection{Analysis of fracture pattern}

The fracture surfaces for the various surface structures samples are shown in Figure 8. In Figure 8a a representative selection of general failure patterns on the thick sheet and in Figure 8b more detailed images from chosen fracture areas are given. In general, all samples show a fracture within the $\mathrm{ZnNi}$ layer close to the substrate on the thin sheet. Repeated cracks in the adhesive running from the edge to the center are visible in the peeling feed direction (Fig. 8a). These ends in a central adhesive crack with a zipper-like shape. The micrographs (Fig. 8b) show typical fracture lines transverse to the peeling feed direction. It can be also seen a slightly accumulation of these fracture lines in the layer direct before crack initiation in the adhesive material. A highresolution image of the laser structured fracture surface (Fig. 8c) shows a periodic grid pattern with a repetition of a few $\mu \mathrm{m}$. The other surface structured variants do not show this pattern.

\section{Discussion}

Angle dispersive XRD analysis of the $\mathrm{ZnNi}$ layer confirms the preferred gamma $(\gamma)$ phase as expected. In addition, the residual stresses in the $\mathrm{ZnNi}$ layer could investigated by using the $\sin ^{2} \psi$ method. The results of about $+50 \mathrm{MPa}$ in longitudinal and transverse confirms result of other investigations with alternative analysis procedures [13,15].

An SEM analysis of the crystal structures confirms the perpendicular nucleation described by Münninghoff et al. [14] and Chao-hong et al. [16] for electrodeposited Zn layers also in the case of ZnNi layers investigated in this study. Furthermore, the crystalline structure also follows this perpendicular growth direction, when the surface structure has the shape of the chosen convex contour. This contour guided crystalline growth formation is shown in Figure 6. Referring to the convex contour, the desired crosslinked crystalline structure, assumed in Figure 1a, can be nearly achieved.

The analysis of the fracture patterns in Figure 8a shows a general fracture pattern in the $\mathrm{ZnNi}$ layer close to the substrate with cracks in the adhesive in areas of local stress overload. With a decreasing peel line width to the center, these cracks repeat under continuous peeling load and create the typical repeated zipper-shaped pattern. This typical fracture pattern is present in all peeled samples with the measured slight residual tensile stress regardless of the applied surface structure. However, in a more precise comparison, differences can be seen in the local frequency of these incipient cracks (Fig. 8a). The rougher surface structures of the untreated, grinded and laser structured samples, show significantly fewer incipient crack points compared to the polished one. SEM analyses confirm the small and locally crosslinked crystalline structure especially for the grinded and laser structured variants in Figures $6 \mathrm{c}$ and $6 \mathrm{~d}$, which are accompanied by higher strength in the peel test.

\section{Conclusion}

In this study, various surface structures formed on steel sheets by extended direct laser interference patterning (xDLIP) were examined regarding their influence on crystal growth within the applied electrodeposited $\mathrm{ZnNi}$ layer and its mechanical properties. The internal layer strength of the $\mathrm{ZnNi}$ coating was investigated by using roller peel tests according to DIN 1464. 
The test results show that the mechanical strength of structural bonded steel sheets with electrodeposited $\mathrm{ZnNi}$ coatings is limited by the $\mathrm{ZnNi}$ layer itself. The internal strength of the $\mathrm{ZnNi}$ layer is essentially determined by its crystalline orientation and structure.

In detail, the microstructure of the $\mathrm{ZnNi}$ layer show a crystal growth direction, which can be influenced by specific periodic structures applied on the initial steel surface. In case of the specific convex contour investigated here, the crystal growth leads to local crosslinked crystalline structures, which provides a higher resistance to external mechanical stress. This results in a higher peel resistance and a specific fracture pattern with fewer incipient crack points. Initial surfaces, which lead to a lower amount of crosslinked crystalline structures show reduced resistances within roller peel test.

The investigated $\mathrm{xDLIP}$ is a suitable method for periodic surface structuring of steel sheet surfaces with a high ablation rate. Regarding to possible adhesive bonding applications in automotive manufacturing, steel sheet components can be pretreated by local xDLIP to optimize the mechanical strength of the subsequently applied $\mathrm{ZnNi}$ coating.

Acknowledgments. This study was supported with material supplies by ZF Friedrichshafen Group. The authors would like to thank Dr.-Ing Max Schlötter GmbH \& Co KG for carrying out the coating tests, Helmholtz Zentrum Berlin (HZB) for performing the residual stress analysis and Material Engineering Center Saarland (MECS) for conducting the laser structuring tests and the SEM analyses.

\section{References}

1. L. Pathberg, Leichtbau mit Stahl, Erfolgreiche Kombination, https://www.automobil-industrie.vogel.de/leichtbau-mitstahl-erfolgreiche-kombination-a-822197/ (2019) accessed October 19. 2021

2. H. Eichelkraut, Die Entwickler von BMWs Elektroautoi3 erwägen offenbar einen Schritt zurück zum traditionellen Automobilbau, https://www.finanzen.net/nachricht/aktien/ carbon-nicht-mehr-zukunft-bmw-koennte-sich-auf-stahlbesinnen-3809690, (2014) accessed January 29, 2022

3. J. Pietschmann, Industrielle Pulverbeschichtung, Vieweg \& Teubner Verlag, Wiesbaden 2010

4. B. Meuthen, S. Almuth, Coil Coating - Bandbeschichtung Verfahren, Produkte und Märkte, Vieweg Verlag, Wiesbaden, 2008

5. H.J. Koeppen, Galvanotechnik im Spannungsfeld der Automobilindustrie, JOT 2 (2001) 52-54

6. H. Briehl, Chemie der Werkstoffe, Teubner Verlag, Wiesbaden, 2008
7. A. Schönberger, Prognose des Steinschlags und der induzierten Korrosion am Fahrzeug, Ph.D. thesis, University of Erlangen-Nürnberg, 2012

8. J. Gochermann, K. Roth, Forschungsagenda Oberflächentechnik, DFO Service GmbH, Neuss 2007 (unpublished)

9. G. Basner, Festigkeitsverhalten von Klebeverbindungen aus galvanisch sowie feuerverzinkten Blechen, Ph.D. thesis, University of Paderborn, 1986

10. K. Kroos, Analyse der Grenzschichtstruktur und der Eigenschaften von Klebeverbindungen mit verzinkten Feinblechen, Ph.D. thesis, University of Paderborn, 1990

11. J. Stahl, Kleben auf stückverzinkten Oberflächen, Ph.D. thesis, University of Kaiserslautern, 2015

12. C. Schade, H. Käszmann, Korrosionsschutz der Spitzenklasse - Galvanisch abgeschiedenes Zink-Nickel auf Eisenwerkstoffen, Womag 2 (2013) 23

13. N. Lotfi, M. Aliofkhazraei, H. Rahmani, Zinc-nickel alloy electrodeposition: characterization, properties, multilayers and composites, Prot. Metals Phys. Chem. Surf. (2018) 1-26

14. T.R. Münninghoff, M.M. Lohrengel, Keimbildungskinetik in technischen Zink- und Zink-Nickel-Legierungselektrolyten, Galvanotechnik 3 (2010) 509-514

15. T. Oriti, A comparative study of gamma-phase zinc-nickel deposits electroplated from various alkaline and acid systems, NASF Surface Technol. 79 (2014) 1-15

16. W. Chao-hong, C. Hsien-hsin, L. Po-yi, C. Po-yen, Kinetic analysis of Ni5Zn21 growth at the interface between Sn-Zn solders and Ni, Intermetallics 22 (2021) 166-175

17. G. Pedroza, C. de Souza, M. de Jesus, L. de Andrade Lima, D. Ribeiro, Influence of formic acid on the microstructure and corrosion resistance of $\mathrm{Zn}-\mathrm{Ni}$ alloy coatings by electrodeposition, Surf. Coat. Technol. 258 (2014) 232-239

18. H. Conrad, J. Corbett, T. Golden, Electrochemical deposition of $\gamma$-phase zinc-nickel alloys from alkaline solution, J. Electromech. Soc. 159 (2021) 85-95

19. C. Bishop, A. Rousseau, V. Opaskar, Gamma phase zinc nickel electrodeposits from alkaline electrolyte, SAE Technical Paper Series 01 (2005), 1-11

20. J. Unruh, Struktur galvanischer Niederschläge, Galvanotechnik 5 (1997) 1492-1497

21. A.M. Kietzig, C. Grambow, K. Ahmmed, Fabrication of micro/nano structures on metals by femtosecond laser micromachinig, Micromachines 5 (2014) 1219-1253

22. M. D'Alessandria, A. Lasagni, F. Mücklich, Direct micropattering of aluminium substrates via laser interference metallurgy, Appl. Surf. Sci. 255 (2018), 3210-3216

23. M. El-Khoury, M. Seifert, S. Bretschneider, Hybrid processing of bearing steel by combining direct laser interference patterning and laser hardening for wear resistance applications, Mater. Lett. 303 (2021) 130284 1-4

24. F. Mücklich, A. Lasagni, C. Daniel, Laser Interference Metallurgy - using interference as a tool for micro/ nano structuring, Int. J. Mater. Res. 97, 10 (2006) 1337-1344

Cite this article as: Christian Stelter, Stefan Dieckhoff, Influence of laser surface structuring of steel sheets on the mechanical properties of electrodeposited ZnNi coatings, Manufacturing Rev. 9, 6 (2022) 